\title{
COMO O PACIENTE HOSPITALIZADO PERCEBE O AMBIENTE DE SUA UNIDADE
}

\author{
Clarinda Takito ${ }^{1}$
}

\begin{abstract}
RESUMO. Existe em enfermagem a preocupação relacionada com as condições ambientais oferecidas ao paciente hospitalizado. As condições oferecidas devem contribuir para o bem estar e recuperação da saúde do indivíduo. Para tanto foi realizado estudo de uma situação a partir da percepção do paciente sobre esta. Com o objetivo de identificar o grau de satisfação dos pacientes com o ambiente e as condições ambientais por eles percebidas como mais e menos agradáveis, foram entrevistados 58 pacientes internados num hospital-escola governamental. Análise das respostas obtidas, mostrou que as condições hospitalares oferecidas atendem às necessidades de ambiente em $81 \%$ dos pacientes, que demonstraram pelas respostas um alto grau de satisfação. As condiçס̄es maís agradáveis, isto é, aquelas que apresentam menor índice de problemas estão relacionadas a iluminação, conforto térmico, móveis e equipamentos. As menos agradáveis estáo relacionadas a condições gerais (territorialidade, agradabilidade, conforto e lim$p \in z d$ ); privacidade e silêncio; comunicação. $O$ estudo oferece subsídios à enfermeira que atua tanto no cuidado direto como em planejamento e organização dos espaços para os pacientes hospitalizados e à docente que prepara o aluno para atuar na vida protissional.
\end{abstract}

ABSTRACT. There is in nursing a preoccupation with environmental conditions of interned patient. These conditions should help the patient to recovery and welfare. The study was realized to know patients' perception about the unit. The goal was to verify the satisfaction degree of patients, the environmental conditions viewed as more agreeable and desagreeable. The author interviewed 58 patients from governmental hospital. The results showed the hospital conditions were useful to $81 \%$ of patients who had high degree satisfaction. The agreeable conditions, which had few problems, were illumination, thermic confort, mobile and equipments. The desagreeable conditions were general conditions (local, pleasure, comfort and housekeeping); closeness, silence communication. This study presents framework for nurses who care patient and planning local to patient and to teacher-curse in preparing her student to professionat life.

\section{INTRODUÇAOO}

$\mathrm{Na}$ classificação formulada por HORTA ${ }^{6}$, o ambiente, tanto físico como psicossocial, faz parte do elenco das necessidades básicas do homem. Daí a importância do estudo das influências do ambiente no paciente hospitalizado e da formulação de propostas que visem melhorar a condição ambiental dentro de nossa realidade.

Dada a complexidade do assunto, por envolver aspectos físicos e psicossociais, trata este trabalho de estudar apenas a percepção do ambiente pelo paciente hospitalizado.

Os fatores que influenciaram na escolha deste tema de estudo foram a sua importância

1. Auxiliar de Ensino, disciplina de Fundamentos de Enfermagem, Escola de Enfermagem da Universida. de de São Paulo. 
pela influência direta e indireta no paciente, confirmada por diversos autores: HARMER \& HENDERSON ${ }^{4}$, FUERST ${ }^{3}$, SOMMER ${ }^{8}$, HEIMSTRA $^{5}$, BELAND \& PASSOS ${ }^{1}$; c interesse particular do autor em subsidiar estudos relativos à organização do espaço para 0 paciente hospitalizado; despertar nos alunos de enfermagem o interesse pelo assunto, uma vez que, como futuros profissionais, serão os elementos de ligação entre o paciente e os responsáveis pela organização hospitalar.

O assunto necessidade humana básica de ambiente faz parte do conteúdo programático desenvolvido com os alunos nas disciplinas de Introdução e Fundamentos de Enfermagem, e interessa ao ensino e à prática porque prepara os alunos para atuarem na vida profissional, tanto no cuidado direto ao paciente como em ações administrativas e de planejamento que envolvam decisões relativas à organização do ambiente para o paciente hospitalizado.

Neste trabalho, a necessidade humana de ambiente é estudada, verificando-se qual a opinião dos pacientes à condição ambiental oferecida.

Visando associar a teoria à realidade de campo, os alunos foram envolvidos na pesquisa da seguinte forma: um grupo de alunos fez a coleta de dados e apresentou à classe uma análise comparativa das proposições bibliográficas com os resultados obtidos e as experiências pessoais na realização das entrevistas com os pacientes.

\section{OBJETIVOS}

- Identificar o grau de satisfação dos pacientes hospitalizados relacionado ao número de respostas favoráveis, numa condição ambiental oferecida.

- Verificar o número de respostas favoráveis e desfavoráveis dadas pelos pacientes às variáveis - condições gerais de ambiente e espaço; móveis e equipamentos; iluminação; conforto térmico (ventilação e temperatura); privacidade e silêncio; comunicação.

- Identificar as condições ambientais que os pacientes consideram mais agradáveis e as menos agradáveis.

\section{METODOLOGIA}

\section{Campo de estudo}

O trabalho foi realizado num hospital estatal de ensino especializado, onde as unidades. de internação são constituídas por quartos de dois leitos com banheiro privativo, padronizados quanto à forma, dimensões e mobiliário.

\section{Descrição do ambiente físico}

\section{Localização}

As unidades de internação onde se localizam os quartos, campo do presente estudo, ocupam o quinto e sétimo andares de um edifício hospitalar composto de onze pavimentos, sendo um subsolo, térreo 1 , térreo 2 , mezanino e mais sete andares.

Quanto à orientação solar, a metade do número de quartos tem suas aberturas voltadas para a face sul e a outra metade para a face norte.

\section{Acessos}

Os quartos comunicam-se de um lado com o corredor interno de circulação de serviço e de outro com o corredor externo de circulação de pacientes (Figura 1).

\section{Móveis e equipamentos}

Cada unidade de paciente é constituída por cama, cadeira, mesa de cabeceira, mesa de refeição, escadinha de um degrau, painel de serviço (Figura 2) - contendo dois pontos de oxigênio, dois pontos de vácuo, uma tomada de 220V; quatro tomadas de $110 \mathrm{~V}$ e dois interfones; - cortinas em painéis de correr na divisória e porta de vidro que dá acesso ao corredor de circulação de pacientes e um armário embutido.

O banheiro é constituído por um "box" com chuveiro, um lavatório e um vaso sanitário.

\section{Iluminação}

Os quartos recebem iluminação natural através da divisória e porta de vidro que dá acesso ao corredor externo de circulação de pacientes. A iluminação artificial é direta, através de duas luminárias embutidas no forro de alumínio, com duas lâmpadas fluorescentes cada e aletas difusoras. O quarto dispõe ainda de um foco fixo por leito, na cabeceira, regulável, para exames e leituras. $\mathrm{O}$ interruptor das lâmpadas do teto fica próximo à porta de acesso junto ao corredor de serviço e o interruptor do foco fica no painel de serviço, junto à cabeceira da cama.

Estrutura e material de acabamento

A separação entre um quarto e outro é feita por divisões leves, de madeira, revestidas 


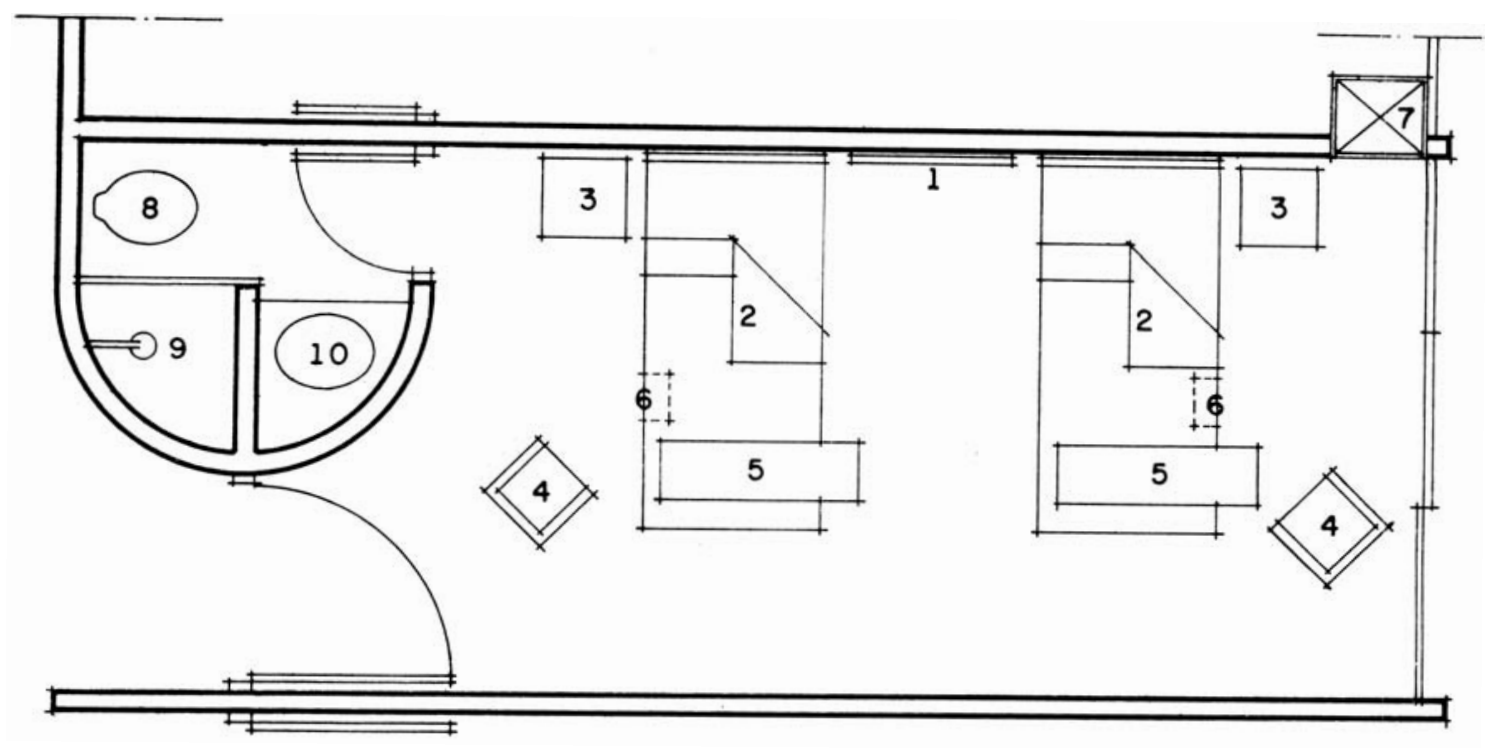

Figura 1. Quarto para dois pacientes. Plania esquemática. Esc. 1:30. Legenda: 1. Painel de serviço (Figura 2); 2. Leito hospitalar; 3. Mesa de cabeceira; 4. Cadeira; 5. Mesa para refeições; 6. Escadinha; 7. Armário; 8. W.C.; 9. Chuveiro; 10. Lavatório.

com laminado fenólico melamínico, tipo "fórmica" na cor cinza. O banheiro, que divide o quarto e a circulação de serviço é executado em alvenaria, revestido com laminado fenólico melamínico, na cor azul. Conforme já foi mencionado no item Móveis e Equipamentos, a divisória que separa o quarto do corredor externo de circulação de pacientes é de vidro comum com caixilho de alumínio.

O piso é revestido de placas de material vinílico, na cor azul.

O forro é de alumínio, tipo "luxaloom", na cor gelo.

Dimensões dos quartos e banheiros

Cada quarto tem $5,90 \mathrm{~m}$ de largura por 2,80 $\mathrm{m}$ de comprimento, correspondendo a uma área total de $15,12 \mathrm{~m}^{2}$, o que resulta uma média de $7,56 \mathrm{~m}^{2}$ por leito. A área do banheiro é de $2,80 \mathrm{~m}^{2}$, perfazendo uma área global de $17,92 \mathrm{~m}^{2}$, de uso exclusivo dos pacientes de cada unidade.

Sistema de comunicação

A comunicação do paciente com a enfermagem é feita através de interfone localizado no painel de serviço cuja central se localiza no posto de enfermagem. O sistema é provido de um cabo e na extremidade uma pera com botão para chamada da enfermagem através da sinalização luminosa na central e na porta do quarto correspondente. Estabelecido o con-

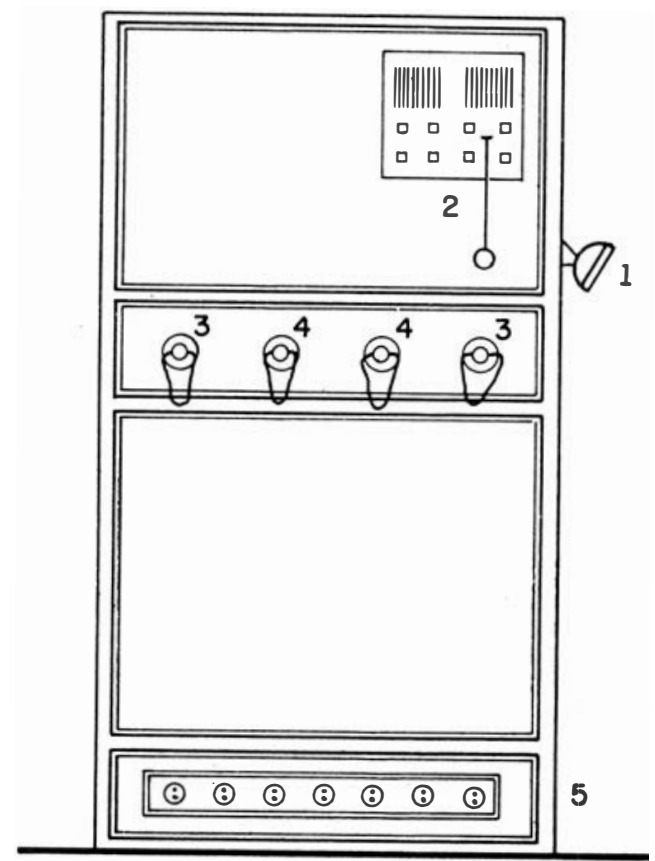

Figura 2. Painel de serviço. Legenda: 1. Foco; 2. Campainha; 3. Oxigênio; 4. Vácuo; 5. Tomadas.

tato inicial a comunicação é verbal, por interfone, entre o paciente e a enfermagem.

\section{Ventilação}

A ventilação cruzada é feita através da porta de acesso ao corredor interno de circulação de serviço e da porta que dá acesso ao corredor externo de circulação de pacientes, ajudada ainda por uma janela basculante da 
divisória de vidro, cujas dimensões são de 0,82 m de largura por 0,72 de altura.

Completando a descrição feita segue a representação gráfica do quarto e painel de serviço.

\section{População de estudo}

\section{Critérios de seleção}

A população foi selecionada dentro dos seguintes critérios:

- Pacientes de ambos os sexos, conscientes e em condições de manter uma entrevista;

- Adultos com idade entre vinte a sessenta anos. Foi delimitada esta faixa etária pelas diferenças significativas que há entre jovens de menos de vinte anos e indivíduos de mais de sessenta. KAMIYAMA?

- Com tempo de internação entre 48 horas e até trinta dias para permitir um período de adaptação e evitar as características do paciente institucionalizado pela longa permanência no hospital.

\section{Características}

Por não constituir objetivo do estudo as características da população são apresentadas apenas descritivamente.

A população estudada foi de 58 pacientes internados e selecionados segundo os critérios descritos no item precedente.

Dos 58 pacientes, $32(55,17 \%)$ eram homens e $26(44,83 \%)$ mulheres; $48(82,76 \%)$ procediam de São Paulo e dez $(17,24 \%)$ de outros estados.

Apenas quinze $(25,86 \%)$ não tinham experiência de hospitalização anterior.

Quanto à instrução, trinta pacientes $(51,72 \%)$ situavam-se na faixa de primeiro grau, vinte $(34,48 \%)$ na faixa do segundo grau, cinco $(8,62 \%)$ tinham curso universitário e apenas três $(5,17 \%)$ eram analíabetos.

Como o hospital, campo da presente pesquisa, mantém convênio com o INAMPS, 45 pacientes $(77,59 \%)$ eram previdenciários. Os restantes, classificados dentro do critério estabelecido para seleção econômico-social do hospital, onde há uma graduação para pagamento que vai de 0 a 10 , representando 0 a categoria não pagante e 1 a categoria que contribui com o pagamento da medicação quando em tratamento de ambulatório. Os restantes, de 2 a 10, seguem um escalonamento gradativo de taxas, não detalhado neste trabalho por nenhum dos pacientes pesquisados ter sido enquadrado nestes graus. Dos catorze pacientes enquadrados na classificação econômicosocial do hospital, cinco $(8,62 \%)$ pertenciam à categoria 0 e oito $(13,79 \%)$ à categoria 1 .

O tempo médio de internação, por ocasião da entrevista, foi de doze dias.

A distribuição dos pacientes segundo a faixa etária foi a seguinte: dezoito a trinta anos, treze pacientes $(22,41 \%)$; 31 a 40 anos, nove pacientes $(15,52 \%) ; 41$ a 50 anos, quinze pacientes $(29,86 \%)$, e 51 a 60 anos, 21 pacientes $(36,21 \%)$. A maior concentração de pacientes em relação à idade ocorreu nas duas últimas faixas etárias estando 36 pacientes, isto é, $62,07 \%$ da população, entre 41 e 60 anos.

\section{Técnica utilizada}

Para coleta de dados foi elaborado um formulário (Anexo 1) contendo 22 questões, sendo cinco questões abertas e dezessete fechadas. Os assuntos abordados nas questões são os seguintes: agradabilidade, espaço, territorialidade, móveis e equipamentos, iluminação, privacidade, ruídos, ventilação, temperatura, limpeza e comunicação.

Os formulários foram preenchidos através de entrevista realizada com os pacientes por seis alunos da disciplina de Introdução à Enfermagem, treinados previamente.

$\mathrm{O}$ estudo piloto foi realizado em uma unidade de internação de outro hospital governamental, com características físicas e de população que têm alguma semelhança com o campo e a população em estudo.

As entrevistas foram realizadas nos dias 11 de setembro e 26 de outubro de 1981, com intervalo de 46 dias entre a primeira e a segunda coleta, cuidado que se tomou para não haver interferência por comunicação entre os pacientes.

Nas duas ocasiões foram entrevistados todos os pacientes internados que preenchiam os critérios de seleção, mencionados no item Critérios de Seleção.

\section{Interpretação de dados}

No instrumento utilizado, dezessete das 22 questões são fechadas e as respostas dadas pelos pacientes são classificadas em dois grupos: favoráveis e desfavoráveis.

São consideradas respostas favoráveis aquelas que implicam em aceitação por parte do paciente, das condições ambientais oferecidas, significando ausência de problemas. São consideradas respostas desfavoráveis aquelas 
que implicam em não aceitação por parte do paciente, das condições ambientais oferecidas, significando a presença de problema. Por exemplo, na questão n. ${ }^{\circ} 3$, onde é perguntado se o espaço do quarto é suficiente para se sentir bem acomodado, a resposta SIM é considerada favorável e a resposta NÃO é desfavorável.

Sempre após uma resposta desfavorável dada pelos pacientes foi perguntado "por quê?" e as justificativas apresentadas são comentadas no item Resultados e Discussão.

O grau de satisfação, dos pacientes é dado pelo número de respostas favoráveis categorizadas de 0 a $100 \%$ em quatro intervalos de classes de $25 \%$ cada uma, segundo critério adotado por STAPE ${ }^{9}$ :

\section{Percentual de respostas favoráveis - grau de satisfação}

0 a $25 \%$ - insatisfeito

25 a $50 \%$ - baixo grau de satisfação

50 a $75 \%$ - médio grau de satisfação

75 a $100 \%$ - alto grau de satisfação

Das dezessete questões fechadas, tomadas como indicadores, foram estabelecidas seis variáveis independentes:
- Condições gerais de ambiente e espaço (questões 3, 5, 6, 7 e 18);

- Móveis e equipamentos (questões 8, 9 e 11);

- Iluminação (questões 12 e 13);

- Conforto térmico (questões 16 e 17);

- Privacidade e silêncio (questões 14 e 15);

- Comunicação (questões 19, 20 e 21).

Os resultados obtidos nas seguintes questões abertas: n..$^{\circ} 1$ e 2 , relativas à percepção das condições ambientais mais e menos agradáveis; $n .^{\circ} 4$, relativa à territorialidade; $n .^{\circ}$ 10 , relativa à utilização de equipamento, são apresentados em três tabelas.

As respostas obtidas na questão n. ${ }^{\circ} 22$ foram utilizadas para complementação das questões anteriores.

Os resultados são apresentados em freqüências relativas e absolutas.

\section{RESULTADOS E DISCUSSÃO}

Os 58 pacientes responderam todas as $\mathbf{2 2}$ questões contidas no instrumento. Os resultados obtidos estão apresentados nas cinco tabelas a seguir.

TABELA 1 - Número e percentagem de pacientes por sexo, segundo grau de satisfação em relação às condições ambientais oferecidas.

\begin{tabular}{|c|c|c|c|c|c|c|c|c|}
\hline \multirow[b]{2}{*}{$\begin{array}{l}\text { Grau de } \\
\text { satisfação }\end{array}$} & \multirow[b]{2}{*}{ em ${ }^{\circ}$} & \multirow[t]{2}{*}{ Pacientes } & \multicolumn{2}{|c|}{ Masculino } & \multicolumn{2}{|c|}{ Feminino } & \multicolumn{2}{|c|}{ Total } \\
\hline & & & N. ${ }^{\circ}$ & $\%$ & N. & $\%$ & N. & $\%$ \\
\hline $\begin{array}{r}0 \\
25 \\
50 \\
75 \\
\end{array}$ & - & $\begin{array}{r}25 \\
50 \\
75 \\
100\end{array}$ & $\begin{array}{r}1 \\
5 \\
26\end{array}$ & $\begin{array}{r}3,17 \\
15,62 \\
81,25\end{array}$ & $\begin{array}{r}5 \\
21 \\
\end{array}$ & $\begin{array}{l}19,23 \\
80,77\end{array}$ & $\begin{array}{r}1 \\
10 \\
47\end{array}$ & $\begin{array}{r}1,72 \\
17,24 \\
81,04\end{array}$ \\
\hline Total & & & 32 & 100 & 26 & 100 & 58 & 100 \\
\hline
\end{tabular}

TABELA 2 - Número e percentagem de respostas favoráveis e desfavoráveis segundo condições ambientais oferecidas.

\begin{tabular}{|c|c|c|c|c|c|c|}
\hline \multirow[b]{2}{*}{$\begin{array}{l}\text { Condições } \\
\text { ambientais }\end{array}$} & \multicolumn{2}{|c|}{ Favoráveis } & \multicolumn{2}{|c|}{ Desfavoráveis } & \multicolumn{2}{|c|}{ Total } \\
\hline & N. ${ }^{\circ}$ & $\%$ & N. ${ }^{\circ}$ & $\%$ & N. ${ }^{\circ}$ & $\%$ \\
\hline $\begin{array}{l}\text { Condições gerais de } \\
\text { ambiente e espaço } \\
\text { Móveis e equipamentos } \\
\text { iluminação } \\
\text { Conforto tẽrmico } \\
\text { Privacidade e silêncio } \\
\text { Comunicação }\end{array}$ & $\begin{array}{r}229 \\
151 \\
361 \\
104 \\
92 \\
141\end{array}$ & $\begin{array}{l}77,10 \\
87,28 \\
93,28 \\
89,65 \\
79,31 \\
81,03\end{array}$ & $\begin{array}{l}68 \\
22 \\
26 \\
12 \\
24 \\
33\end{array}$ & $\begin{array}{r}22,90 \\
12,72 \\
6,72 \\
10,35 \\
20,69 \\
18,97\end{array}$ & $\begin{array}{l}297 \\
173 \\
387 \\
116 \\
116 \\
174\end{array}$ & $\begin{array}{l}100 \\
100 \\
100 \\
100 \\
100 \\
100\end{array}$ \\
\hline Total & 1.078 & 85,35 & 185 & 14,65 & 1.263 & 100 \\
\hline
\end{tabular}

Dos 58 casos entrevistados $47(81,04 \%)$ tiveram um número de respostas favoráveis entre 75 a $100 \%$, o que permite categorizar esta população em alto grau de satisfação às condições ambientais of erecidas.

A diferença entre o número de pacientes 
de ambos os sexos é de apenas $0,48 \%$. Nenhum paciente teve número inferior a $25 \%$ de respostas favoráveis às questões formuladas.

Apenas quatro pacientes responderam favoravelmente a $100 \%$ das questões. Estes pacientes, dois homens e duas mulheres, pertencem à classificação social previdenciária, três têm instrução na faixa de primeiro grau e um é analfabeto.

Dos quinze pacientes que não tinham experiência de hospitalização anterior, treze $(86,67 \%)$ situaram-se entre os que tiveram respostas favoráveis entre 75 a $100 \%$. Das 1.263 respostas obtidas, $1.078(83,35 \%)$ foram favoráveis e $185(14,65 \%)$ foram desfavoráveis às condições ambientais oferecidas.

Condições gerais de ambiente e espaço Esta variável, composta pelas questões $3,5,6$, 7 e 18, relativas à territorialidade, agradabilidade, conforto e limpeza, foi a que obteve o menor índice de respostas favoráveis, 229 respostas $(77,10 \%)$.

As justificativas dadas pelos pacientes, às $68(22,90 \%)$ respostas desfavoráveis, são comentadas a seguir e não estão apresentadas em tabela. Foram citadas 29 diferentes justificativas pelos pacientes. Observou-se que 26 delas $(89,65 \%)$ foram referentes às necessidades psicossociais, principalmente de recreação, gregária, de amor e de atenção, e apenas três justificativas $(10,35 \%)$ foram relativas às necessidades psicobiológicas de ambiente e espaço. $\mathrm{Na}$ questão 7,36 pacientes $(62,07 \%)$ dos 58 entrevistados responderam que gostariam de trazer objetos para tornar seu quarto mais agradável, tais como rádio, televisão, flores e objetos religiosos.

Foram referidos problemas de isolamento, saudades dos familiares, demora no atendimento às solicitações feitas através do sistema de comunicação, restrições à liberdade, dificuldade de adaptação à cama e travesseiro, distância do leito à campainha.

Não foi citado pelos pacientes nenhum problema relativo ao espaço físico em si, entretanto, foi constatado que as dimensões dos quartos não estão de acordo com as dimensões mínimas estabelecidas nas normas do Ministério da Saúde ${ }^{2}$, que preconizam $1,50 \mathrm{~m}^{2}$ de afastamento dos pés da cama à parede, cmbora a área mínima de $7 \mathrm{~m}^{2}$ por leito tenha sido atendida.

No instrumento utilizado para coleta de dados não foi incluída nenhuma questão sobre cores. A falta deste indicador impede analisar a influência deste fator sobre os pacientes, embora se saiba que os quartos não têm de- coração e as cores predominantes são cinza e azul. Sugere-se que este indicador seja incluído em próximos estudos.

Móveis e equipamentos - As justificativas dadas pelos pacientes às 22 respostas $(12,72 \%)$ desfavoráveis foram incômodo provocado pela capa plástica do colchão, roupas de cama com mau cheiro, localização inadequada do armário em relação ao leito. Apenas um paciente reclamou da altura excessiva da çama; este número causa estranheza, quando se sabe que a altura do leito hospitalar é determinada em função da conveniência da equipe de saúde e é diferente das camas utilizadas nos domicílios, FUERST ${ }^{3}$. Entretanto, a presença da escadinha de um degrau talvez contribua para que $o$ paciente aceite esta condição como sendo normal, uma vez que a escadinha diminui o possível desconforto provocado pela altura na utilização da cama.

Iluminação - Esta variável, entre todas, foi a que obteve maior número de respostas favoráveis, $361(93,28 \%)$, e apenas $26(6,72 \%)$ foram desfavoráveis. As justificativas dadas pelos pacientes às respostas desfavoráveis foram relativas à dificuldade para controlar sozinho a iluminação artificial devido à localização dos interruptores em relação ao leito.

Conforto térmico - $\mathrm{O}$ número de respostas favoráveis aos indicadores ventilação e temperatura, questões n.'s 16 e 17, foi de 104 respostas $(89,65 \%)$. As respostas desfavoráveis, doze $(10,35 \%)$ foram dadas na maioria por homens. As justificativas apresentadas pelos pacientes foram o calor e a ventilação insuficiente do quarto no período noturno, uma vez que neste período as portas são fechadas e a ventilação é feita apenas através da janela basculante.

Privacidade e silêncio - Das 116 respostas à esta variável, $24(20,69 \%)$ foram desfavoráveis. A principal justificativa apontada nas respostas desfavoráveis ao indicador ruidos, pelos pacientes, foram os ruídos provocados nos quartos vizinhos por choro de criança, tosse, ressonar, televisão ligada. Este resultado era esperado, uma vez que descrevemos como características do ambiente em estudo paredes constituídas por divisórias leves, de madeira, revestidas de "fórmica" e forro de alumínio. Os ruídos provocados num quarto são percebidos com nitidez no outro. Estes materiais, embora favoreçam a flexibilidade hospitalar, não se constituem bons isolantes acústicos quando não tratados adequadamente e quando utilizados em hospital podem diminuir o con- 
forto dos pacientes e interferir em sua necessidade de repouso.

A principal justificativa citada como desfavorável ao indicador privacidade foi a circulação no quarto pela equipe de saúde e por outros pacientes, do corredor de circulação de serviço ao corredor de circulação de pacientes. Nas unidades de internação em estudo não há comunicação entre estas duas áreas a não ser passando pelos quartos dos pacientes.

Comunicação - Nesta variável o número de respostas favoráveis foi de $141(81,03 \%)$ e 33 respostas $(18,93 \%)$ foram desfavoráveis. Entretanto, as questões 19, 20 e 21, que compuseram esta variável tiveram diferença significativa nas respostas.

Foi feita uma análise das respostas dadas pelos pacientes a estas questões e os dados apresentados a seguir não constam em tabela. Dos 58 pacientes entrevistados, 53 pacientes $(91,38 \%)$ responderam favoravelmente à questão 19 sobre meio de comunicação e o mesmo número, 53 pacientes $(91,38 \%)$, respondeu favoravelmente à questão 20 sobre atenção recebida; apenas 35 pacientes $(60,34 \%)$ deram respostas favoráveis à questão 21 sobre rotinas. A principal justificativa apontada pelos 23 pacientes $(39,66 \%)$ que deram respostas desfavoráveis foi relativa à visita - número restrito de pessoas, tempo curto de permanência e horário impróprio para as visitas. Outros fatores citados como desfavoráveis foram obrigatoriedade do uso de roupa do hospital, horário inadequado das refeições, impossibilidade do uso do telefone para comunicações externas.

A questão 1: "o que mais agrada ao $\mathrm{Sr}$.(a) neste quarto", e a questão 2: "o que menos agrada ao Sr.(a) neste quarto", colocadas aos pacientes logo no início da entrevista obtiveram respostas relativas não só ao quarto mas também ao ambiente hospitalar.
Observa-se que o maior valor encontrado ao que menos agrada foi referente à alimentação, apontada por oito pacientes $(13,79 \%)$. Quanto ao que mais agrada, os móveis e equipamentos foram apontados por onze pacientes $(18,97 \%)$. Entretanto, 25 pacientes $(43,10 \%)$ referiram gostar de "tudo" enquanto que 41 pacientes $(70,70 \%)$ responderam não ter "nada" que os desagrade. Estes valores, pela amplitude das duas variáveis, não permitem uma análise precisa da percepção dos pacientes aos elementos ambientais de seu quarto. Parece que as questões formuladas não deram oportunidade para os pacientes se expressarem de acordo com o objetivo do estudo, que procurava também identificar as condições "que mais agradam", que ficou prejudicado. Sugere-se a reformulação das duas questões com determinação de variáveis e indicadores precisos quando da realização de novos estudos.

TABELA 3 - Número e percentagem de respostas dadas por 58 pacientes às questões "o que mais agrada" segundo condições ambientais.

\begin{tabular}{|c|c|c|c|c|}
\hline \multirow{2}{*}{$\begin{array}{l}\text { Condições } \\
\text { Ambientais }\end{array}$} & \multicolumn{2}{|c|}{ Mais agrada } & \multicolumn{2}{|c|}{ Menos agrada } \\
\hline & N. ${ }^{\circ}$ & $\%$ & N. ${ }^{\circ}$ & $\%$ \\
\hline $\begin{array}{l}\text { Móveis e equipa- } \\
\text { mentos }\end{array}$ & 11 & 18,97 & 2 & 3,45 \\
\hline Atendimento & 5 & 8,62 & 3 & 5.17 \\
\hline Alimentação & - & - & 8 & 13,79 \\
\hline $\begin{array}{l}\text { Limpeza e conser- } \\
\text { vação } \\
\text { Estrutura e locali- }\end{array}$ & 6 & 10,35 & - & - \\
\hline zação & 3 & 5,17 & 2 & 3,45 \\
\hline Liberdade & 4 & 6,90 & 一 & 一 \\
\hline Ruídos & 一 & 一 & 1 & 1,72 \\
\hline $\begin{array}{l}\text { Sistema de comu- } \\
\text { nicação }\end{array}$ & 1 & 1,72 & 一 & - \\
\hline Iluminação & 一 & - & 1 & 1,72 \\
\hline Nada & 3 & 5,17 & 41 & 70,70 \\
\hline Tudo & 25 & 43,10 & 一 & 一 \\
\hline Tot a l & 58 & 100 & 58 & 100 \\
\hline
\end{tabular}

TABELA 4 - Número e percentagem de pacientes por sexo segundo móvels e objetos que os mesmos identificam como sendo seus.

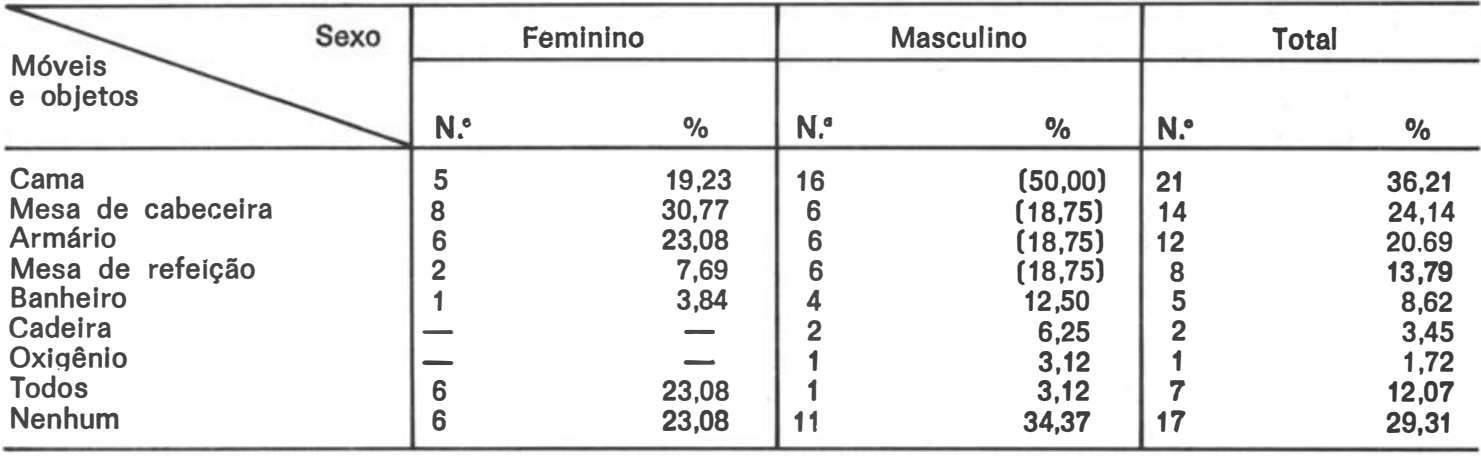


O objetivo desta questão foi a percepção pelos pacientes do ambiente de seu quarto como um território pessoal onde possam conviver com sua intimidade.

SOMMER $^{8}$, em sua abordagem sobre 0 uso do espaço e o direito à intimidade, exemplifica a diferença de atitude do médico que em visita ao paciente, quando no domicílio, anda com humildade e quando no hospital demonstra uma atitude ostensiva. Escreve 0 autor citado "um médico que visita um paciente num hospital fica com o chapéu na cabeça e com o sobretudo, ao caminhar para examinar o paciente. Quando o mesmo médico visita o paciente na casa deste último, entra pela porta da frente com o chapéu na mão, tira o sobretudo e anda com humildade". Refere SOMMER que, embora a defesa do território tenha se ligado a fronteiras visíveis e o espaço pessoal seja uma questão de gestos e posturas, existem situações em que as duas são parte de um único processo - a defesa da intimidade - que inclui o uso do espaço e os direitos da propriedade.

O hábito de invadir o espaço pessoal e territorial dos pacientes hospitalizados ficou demonstrado nos valores obtidos. Apenas sete pacientes $(12,07 \%)$ percebem todos os objetos e móveis como sendo seus. A sensação de estranheza ao ambiente manifestada por dezessete pacientes $(29,31 \%)$ com a resposta "nenhum" é relevante e deve ser considerada ao se planejar o cuidado do paciente.

Houve uma diferença significativa entre os dois sexos quanto à percepção da cama e mesa de cabeceira: dezesseis homens (50\%) percebem a cama como sua, enquanto isto ocorre com apenas cinco mulheres $(19,03)$. Nas questões específicas sobre cama, os problemas de desconforto foram na maioria relatados por mulheres; talvez por isso a maior percepção de propriedade das mulheres tenha recaído no móvel mais próximo e utilitário, a mesa de cabeceira, quando oito mulheres $(30,77 \%)$ a consideram como sua em contraposição a seis homens $(18,75 \%)$.

$\mathrm{O}$ número de móveis e objetos percebidos pelos pacientes como seus, variou de um a quatro: dezoito pacientes citaram um; cinco pacientes citaram dois; nove pacientes citaram três; dois pacientes citaram quatro.

A percepção dos pacientes quanto ao tipo de móveis e objetos foi diversificada. Estão demonstradas no quadro ao lado as frequiências encontradas quando a percepção foi superior a um móvel ou objeto:

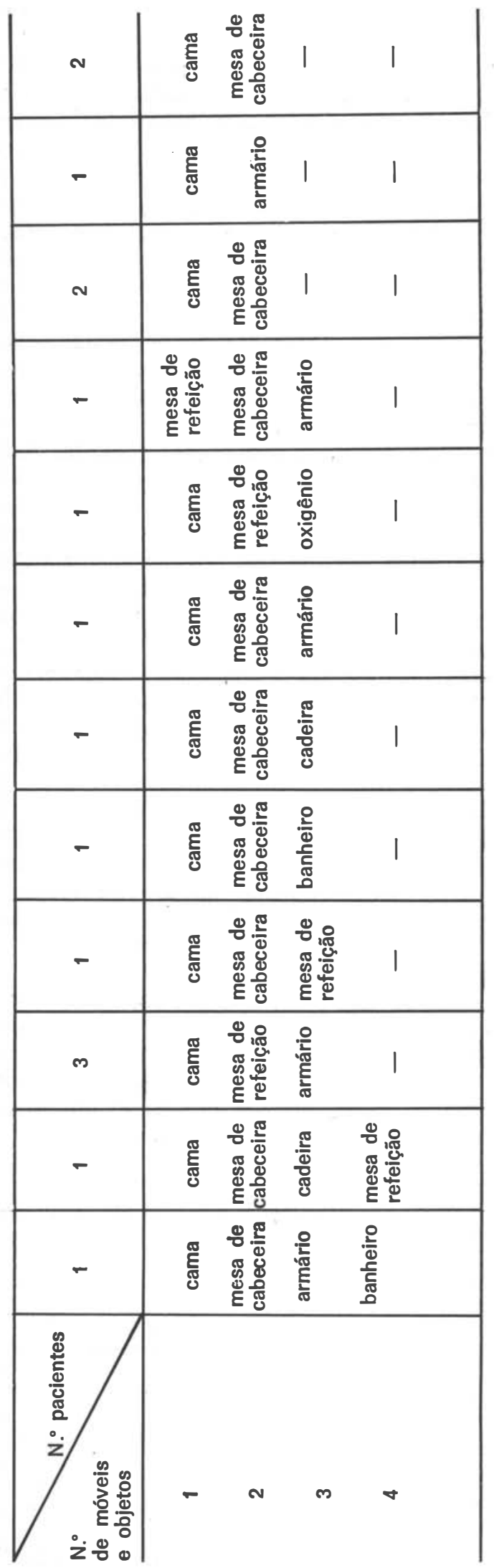


TABELA 5 - Número e percentagem de pacientes por sexo segundo objetos guardados na mesa de cabeceira.

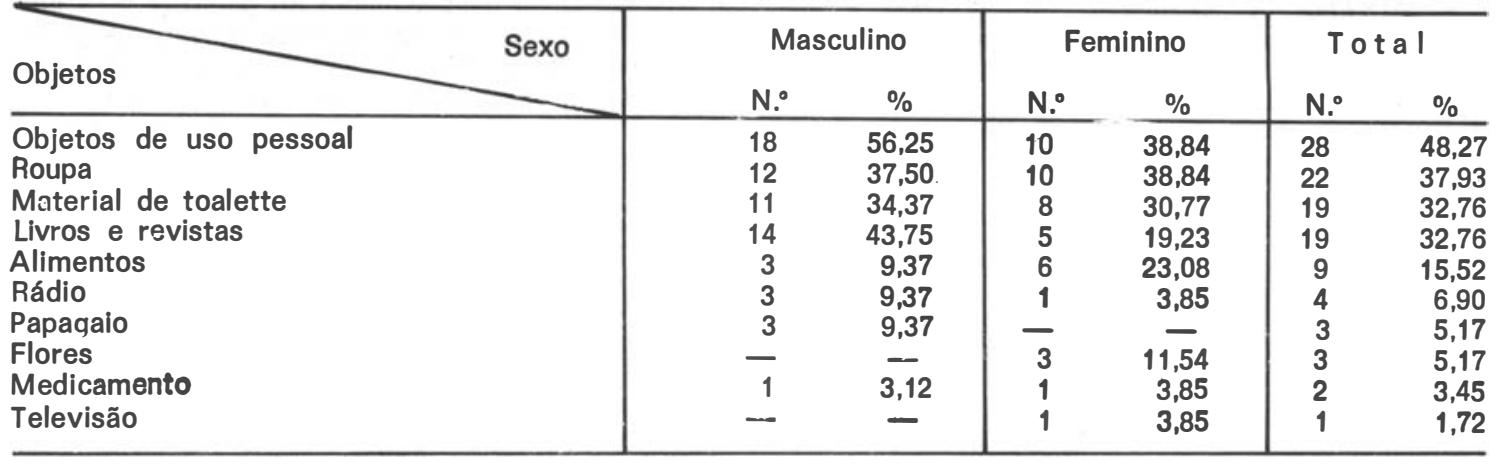

Dos dezoito pacientes que citaram só um móvel, oito pacientes citaram a cama, quatro o armário, três a mesa de cabeceira e três o chuveiro.

A questão, relativa à utilização da mesa de cabeceira (Tabela 5) mostra que, embora no quarto haja um armário, 22 pacientes $(37,93 \%)$ utilizam a mesa de cabeceira para guarda de silas roupas. E interessante lembrar que na variável móveis e equipamentos, da Tabela 2, uma das causas apontadas como desfavoráveis às condições ambientais oferecidas foi a localização do armário em relação ao leito.

Chama atenção a presença de medicamentos na mesa de cabeceira, mas a condição de alguns pacientes exige este tipo de autocuidado.

Os valores obtidos demonstram que à exceção de roupas, alimentos e papagaios, a maioria dos pacientes utiliza adequadamente a mesa de cabeceira.

\section{CONCLUSÃO}

Os dados obtidos levam às seguintes conclusões:

1. O grau de satisfação dos 58 pacientes estudados é -47 pacientes $(81,04 \%)$, alto grau de satisfação; dez pacientes $(17,24 \%)$, médio grau de satisfação: um paciente $(1,72 \%)$, baixo grau de satisfação.

2. O número de respostas favoráveis e desfavoráveis dadas pelos pacientes às variá-

\section{REFERENCIAS}

1. BELAND, I. \& PASSOS, J. Enfermagem clinica. São Paulo. EPU/EDUSP. 1978. v. 1, p. 74-5.

2. BRASIL. Ministério da Saúde. Normas e padrōes de construção e instalações de serviços de saude Brasillia, 1978. p. 48-71.

3. FUERST, E. et alii. Fundamentos de enfermagem. Rio de Janeiro, Interamericana, 1977. p. 145-69. veis estabelecidas é - condições gerais de ambiente e espaço: 229 (77,10\%) respostas favoráveis e $68(22,90 \%)$ desfavoráveis; móveis e equipamentos: $151(87.28 \%)$ respostas favoráveis e $22(12,72 \%)$ respostas desfavoráveis: iluminação: $361(93,28 \%)$ respostas favoráveis e: $26(6,72 \%)$ desfavoráveis; conforto térmico: $104(89,65 \%)$ respostas favoráveis e $12(10,35 \%)$ desfavoráveis; privacidade e silêncio: $92(79,31 \%)$ respostas favoráveis e 24 $(20,69 \%)$ desfavoráveis; comunicação: 141 $(81,03 \%)$ respostas favoráveis e $33(18,97 \%)$ desfavoráveis.

3. As condições ambientais que os pacientes consideram mais agradáveis são - tudo, 25 respostas $(43,10 \%)$; móveis e equipamentos, onze $(18,97 \%)$; limpeza e conservação, seis $(10,35 \%)$; atendimento, cinco $(8,62 \%)$; liberdade, quatro $(6,90 \%)$; estrutura e localização, três $(5,17 \%)$; sistema de comunicação, um $(1,72 \%)$. Dos 58 pacientes, $41(70,70 \%)$ responderam que nada desagrada; os outros pacientes consideram como menos agradáveis as seguintes condições ambientais: alimentação, oito $(13,79 \%)$, atendimento, três $(5,17 \%)$, móveis e equipamentos, dois $(3,45 \%)$, estrutura e localização, dois. $(3,45 \%)$, ruídos, um $(1,72 \%)$, iluminação, um $(1,72 \%)$.

TAKITO, C. As the interned patient viewed the unit environment. Rev. Bras. Enf., Brasilia, 37(2): 125-134, 1984. 
7. KAMIYAMA, Y. O doente hospitalizado e sua percepção quanto à prioridade de seus problemas. São Paulo, 1972. (Tese de doutoramento - Escola de Enfermagem da USP). p. 8.

8. SOMMER, R. Espaço pessoal. São Paulo, EPU/ EDUSP, 1977. p. 49-71, 96-120.
9. STAPE, D. O conhecimento do paciente com alta hospitalar sobre a continuidade do seu tratamento. São Paulo, 1979. (Dissertação de mestrado Escola de Enfermagem da USP). p. 21-22.

\section{ANEXO 1}

Formulário para entrevista a pacientes

\section{Identificação}

Entrevista $n^{\circ}:$

Registro:

$\begin{array}{ll}\text { Leito: } & \text { Andar: } \\ \text { Idade: } & \text { Sexo: }\end{array}$

Nome:

Procedência:

Data de internação:

Experiência de hospitalização anterior:

Classificação econômico-social:

Período relativo a cirurgia: pré-operatório

Data da entrevista: Início:

Instrução:

Dia após internação:

\section{Perguntas:}

1. O que mais agrada ao Sr.(a) neste quarto?

2. O que menos agrada ao Sr.(a) neste quarto?

3. O espaço que o Sr.(a), tem para usar neste quarto é suficiente para se sentir bem acomodado(a)? Sim ( ) Não ( )

4. Quais os móveis e objetos que existem neste auarto o Sr.(a) sente como seus?

5. Teve alguma dificuldade para se acomodar e daí habituar-se ao seu quarto? Sim ( ) Não ( ) Por quê?

6. Que sensação o șeu quarto lhe dá? Segurança () Ansiedade ( ) Conforto ( ) Isolamento ( ) Por quê?

7. Gostaria de trazer alguma coisa para tornar seu quarto mais agradável? Sim ( ) Não ( ) O quê?

8. Teve alguma dificuldade para se acostumar à cama do hospital? Sim ( ) Não ( ) Por quê?

9. A cama é arrumada como o Sr.(a) gosta? Sim ( ) Não (') Por quê?

10. Como tem usado sua mesa de cabeceira?

11. Considera a disposição dos móveis de sua unidade Cômoda ( ) Incômoda ( ) Por quê?

12. Considera a iluminação para: repouso - adequada ( ) Inadequada ( )

leitura - adequada ( ) Inadequada ( )

dormir - adequada ( ) Inadequada ( )

andar - adequada () Inadequada ( )

receber visitas - adequada ( ) Inadequada ( )

nutras atividades - adequada ( ) Inadequada ( )

12. Consegue controlar sozinho(a) a iluminação? Sim ( ) Não ( )

14. O seu quarto the tem proporcionado privacidade? Sim () Não ( ) Por quê?

15. Tem sido incomodado por ruídos? Sim () Não ( ) Quals?

16. Considera a ventilação (abafado, vento encarado): adequada ( ) Inadequada () Por quê?

17. A temperatura de seu quarto é Agradável () Desagradável ( ) Por quê?

18. Como considera a limpeza de seu quarto Otima () Boa () Ruim ( ) Insatisfatória ( )

19. Considera o meio de comunicação (campainha), com a enfermagem Ótimo ( ) Bom ( ) Ruim ( ) Inadequado ( ) Por quê?

20. Considera a atenção que the é dispensada Otima ( ) Boa ( ) Regular ( ) Ruim ( ) Insatisfatória ( ) Por quê?

21. Tem alguma dificuldade com as rotinas do hospital (horários, refeições, visitas, exames, banho, etc.) Sim ( ) Não ( ) Por quê?

22. Gostaria de acrescentar mais alguma coisa? 